\title{
ANALYSIS OF PATTERNS OF BALL RECOVERY IN YOUTH FUTSAL
}

original paper

( ) University School of Physical Education in Wroclaw

DOI: https://doi.org/10.5114/hm.2021.100327

\section{MATHEUS DE LIMA CARNEIRO ${ }^{1}$, MARCOS ANTÔNIO MATTOS DOS REIS ${ }^{1}$, GRÉGORY HALLÉ PETIOT ${ }^{2}$, THIAGO COELHO DE AGUIAR SILVA ${ }^{1}$}

${ }^{1}$ Higher School of Physical Education, University of Pernambuco, Recife, Brazil

${ }^{2}$ Department of Physical Education, Laval University, Québec, Canada

\begin{abstract}
Purpose. To investigate the patterns of recovery of ball possession in a young futsal team.

Methods. Seven games played by a youth futsal team were analysed. Patterns of recovery of ball possession were investigated on the basis of the following variables: way to recover the ball, location of recovery, tactical behaviour after the recovery, and result of the match. One-way ANOVA and post-hoc Tukey honest significant difference test were used to compare the variables. Principal component analysis was also applied to verify the association between variables.

Results. It was observed that there was a greater number of ball recoveries in the defensive sector $\left(F_{3,24}=35.6\right.$; $p<0.001$; $\left.\eta_{\mathrm{p}}^{2}=0.79\right)$, that set pieces were the most frequent way to recover the ball $\left(F_{5,36}=7.9 ; p<0.001 ; \eta_{\mathrm{p}}^{2}=0.46\right)$, that ball possession was maintained more often after the recovery of the ball $\left(F_{3,24}=79.6 ; p<0.001 ; \eta_{\mathrm{p}}^{2}=0.90\right)$, and that there was no correlation between the result of the match and the number of ball recoveries $\left(F_{3,24}=0.20 ; p=0.93 ; \eta_{\mathrm{p}}^{2}=0.10\right)$. Four components were identified that represented a variance of $95 \%$ for all variables. Factor 1 was related to the patterns of ball possession recovery in the offensive sector, while factor 2 was related to the tackle.
\end{abstract}

Conclusions. It was concluded that the way to recover the ball and the location of recovery affected both patterns of recovery and tactical behaviour after the recovery of the ball.

Key words: decision-making, defence, dynamics systems, performance analysis, team sports

\section{Introduction}

Team sports like futsal are characterized by interpersonal coordination, that is, interactions of cooperation and opposition between players in a performance environment with established goals [1-3]. From this, the futsal game can be understood from a systemic approach which perceives teams as open and dynamic systems. Such systems exchange energy and information in order to achieve their goals and adapt to the constant changes in the performance environment $[2,4]$.

To do so, the dynamic systems have order and control parameters. Order reflects the capability of a system to function as a whole, whereas the control parameter causes changes in the order parameter when it reaches a critical threshold $[1,4,5]$. In futsal, an example of order can be the effective space of play, which is defined by the imaginary figure formed by the players positioned on the outskirt of the group of field players and denotes the team's coverage area [1, 6]. The control parameter can be the ball possession recovery, which causes teams to increase the effective space of play in a transition from defence to attack [6-8].

Thus, ball possession recovery consists of the acquisition of the ball by the team that were defending and will be attacking [9-11]. Patterns of ball recovery involve variables such as the way the ball is recovered, the location of the action on the field, and the tactical behaviour of the team after recovery. Moreover, recovery can occur directly, when the defender has the merit of earning the ball, or indirectly, when the team in possession lose the ball [11]. For example, in futsal games, the ball possession recovery by tackle is an important factor for teams to achieve the result of victory in

Correspondence address: Marcos Antônio Mattos dos Reis, Higher School of Physical Education, University of Pernambuco, Street Arnóbio Marquês, 310, Santo Amaro, Recife - PE, Brazil, 50100-130, e-mail: mamreis91@gmail.com

Received: April 23, 2020

Accepted for publication: July 30, 2020

Citation: Carneiro ML, dos Reis MAM, Petiot GH, de Aguiar Silva TC. Analysis of patterns of ball recovery in youth futsal. Hum Mov. 2021;22(3):84-91; doi: https://doi.org/10.5114/hm.2021.100327. 
matches [9]. In a soccer game, a ball recovery caused by a tackle increases by approximately 3 times the offensive effectiveness [10], which is reflected in the difference between top and bottom rank teams in competitions [12-14].

In youth sports, other factors, such as chronological age, also affect the ball possession recovery. For example, competitive futsal players of the under-11 (U-11) age level performed better ball recovery than U-9 and U-7 players [15]. Although older youth players are more likely to perform ball recovery, there is no indication that tactical performance in these transitions in the play will compare adult or professional futsal. This includes the specific causes of ball possession recovery and patterns that emerge in the play. Thus, the purpose of this study was to investigate the patterns of recovery of ball possession in a young futsal team.

\section{Material and methods}

\section{Participants}

The 15 youth futsal players who participated in the study were aged $15-17$ years $(15.93 \pm 0.80)$. They were all affiliated to a U-17 competitive team and regularly took part in formal training and competitions.

As inclusion criteria in the research, the players should have all trained regularly and should have been officially registered in accordance with their local futsal federation rules. In turn, the exclusion criteria involved any injury or other issue that would have impeded the progress of the matches; no player, however, had experienced such an event or was excluded from the study.

\section{Procedures}

Seven futsal games were filmed and analysed as indicated in Figure 1. A Sony W830 camera (20.1 megapixels, high definition; Japan) and a professional tripod (Sl-2111, $1.20 \mathrm{~m}$ ) were installed above the game field to film the matches for their entire duration. The images were transferred to a Samsung notebook and LongoMatch software was used for analysis. The patterns of ball possession recovery were analysed with respect to the following variables: way to recover the ball, location of recovery, and tactical behaviour after the recovery of the ball. The number of ball recoveries

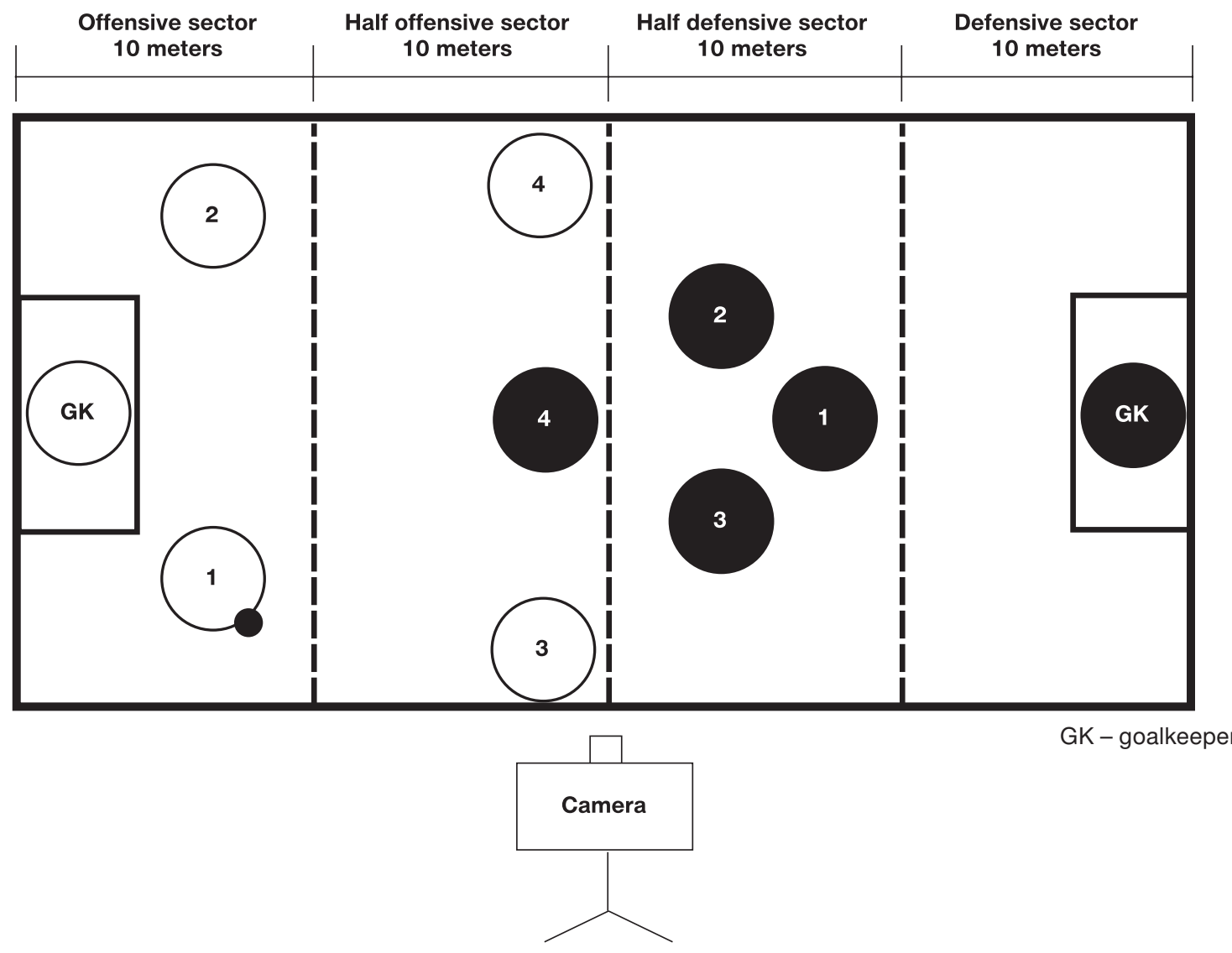

Figure 1. Futsal game (GK +4 vs. $4+$ GK) played in a $40 \times 20$ m field divided into 4 sectors: defensive, half defensive, half offensive, and offensive 
Table 1 . Ways to recover the ball in a futsal game

\begin{tabular}{ll}
\hline Variables & Definition \\
\hline Tackle & Direct contact with the ball carrier \\
Interception & Interruption of a pass or shoot on goal \\
Set piece & Recovery after a set play (e.g. foul) \\
Opponent's error & Unsuccessful action (e.g. pass) \\
Opponent's strike on goal & Unsuccessful strike on goal \\
Save by the goalkeeper & Save or interception by the goalkeeper \\
\hline
\end{tabular}

was also calculated to correlate with the result of the matches.

The ways to recover the ball possession were selected amongst the following: tackle, interception, set piece, opponent's error, opponent's strike on goal, and save by the goalkeeper (see definitions in Table 1). The game field was divided into 4 sectors: defensive, half defensive, half offensive, and offensive, as illustrated in Figure 1, which helped analysing the location of recovery [16]. The tactical behaviours were coded as follows: maintenance of ball possession, counterattack, strike on goal, and scoring goal. Finally, the numbers of ball recoveries were calculated at each new scored goal to help identifying patterns when the teams were winning, drawing, or losing.

\section{Data analysis}

The Kolmogorov-Smirnov test was used to verify the normality of the data distribution $(p>0.05)$. The data were presented as mean (measure of central tendency), standard deviation (measure of dispersion), and coefficient of variation (standard deviation/mean). One-way analysis of variance (ANOVA) was applied to compare the variables. When necessary $(p<0.05)$, posthoc analyses were conducted with the Tukey honest significant difference test. To measure the effect size, the partial squared eta $\left(\eta_{\mathrm{p}}{ }^{2}\right)$ and, when appropriate, Cohen's $d$ (comparison between 2 variables in 1 measure) were used [17].

Principal component analysis (PCA) served to identify the patterns of ball recovery with respect to the way to recover the ball, the location of recovery, the tactical behaviour after recovery, and the result of the match. PCA is a factorial statistical method that allows the identification of groups of variables by decreasing the data dimensions while preserving the maximum variance of the original variables. PCA allows the grouping of the variables into a smaller number of factors $[17,18]$.

The variables were adapted to PCA as the commonality coefficient was equal to or greater than 0.7. Bartlett's sphericity test found correlations between vari- ables [19]. The Kaiser-Meyer-Olkin measure was used to select the factors, and the eigenvalues equal to or above 1 were considered for the retention of factors and the explanation of the data variances [20, 21]. In such a case, the higher the factor load, the higher the correlation between a given variable and a given factor. Therefore, variables with factor loads equal to or above 0.7 were considered to have a strong positive or negative correlation with that given component [17].

Approximately $10 \%$ of randomly selected recovered balls were analysed again in the inter- and intrarater agreements. The temporal distance of the observations of reliability was more than 30 days after the first analysis. Calculations were performed with the kappa test ( $\kappa)$ and the results demonstrated a high degree of agreements (inter-rater: $\kappa=0.89, p<0.001$; intra-rater: $\kappa=0.97, p<0.001$ ) [22]. A significance level of $5 \%$ was adopted, and the statistical software SPSS 20.0 was used to perform all statistical tests.

\section{Ethical approval}

The research related to human use has complied with all the relevant national regulations and institutional policies, has followed the tenets of the Declaration of Helsinki, and has been approved by the ethics committee for studies with human beings at Sergipe Federal University.

\section{Informed consent}

Informed consent has been obtained from the parents and/or legal guardians of all individuals included in this study.

\section{Results}

A total of 466 ball possession recoveries were identified throughout the 7 analysed matches. More ball recoveries occurred in the defensive, half defensive, and half offensive sectors than in the offensive sector. In addition, the defensive sector was where most of the ball recoveries were performed $\left(F_{3,24}=35.6, p<0.001\right.$, $\eta_{\mathrm{p}}{ }^{2}=0.79$ ) (see details in Table 2A). The majority of ball recoveries occurred after set pieces and the fewest were performed when taking advantage of the opponent's error $\left(F_{5,36}=7.9, p<0.001, \eta_{\mathrm{p}}{ }^{2}=0.46\right)$ (Table 2B). The maintenance of ball possession was the tactical behaviour that occurred most frequently after recovering the ball, while scoring goals was the least frequent result $\left(F_{3,24}=79.6, p<0.001, \eta_{\mathrm{p}}{ }^{2}=0.90\right)$ (Table $\left.2 \mathrm{C}\right)$. Finally, there was no significant difference in the number of recovered balls in relation to the match result or the difference of points in the score $\left(F_{3,24}=0.2, p=\right.$ $0.93, \eta_{\mathrm{p}}^{2}=0.10$ ) (Table 2D). 
Table 2. Mean $(M)$, standard deviation $(S D)$, and coefficient of variation $(C V)$ of the number of ball recoveries per (A) sector of play, (B) way to recover the ball, (C) tactical behaviour performed after recovering the ball, and (D) the result of the match

\begin{tabular}{|c|c|c|c|c|c|c|}
\hline \multicolumn{2}{|c|}{ Variables } & \multirow{2}{*}{$\frac{\mathrm{M}}{36.71^{*}}$} & \multirow{2}{*}{$\frac{S D}{11.22}$} & \multirow{2}{*}{$\frac{C V}{0.31}$} & \multirow[t]{2}{*}{$p$} & \multirow[t]{2}{*}{$\eta_{\mathrm{p}}^{2}$} \\
\hline \multirow{4}{*}{ A } & Defensive sector & & & & & \\
\hline & Half defensive sector & 17.29 & 5.12 & 0.30 & \multirow{3}{*}{$<0.001$} & \multirow{3}{*}{0.79} \\
\hline & Half offensive sector & 10.00 & 3.92 & 0.39 & & \\
\hline & Offensive sector & $2.57^{\#}$ & 1.27 & 0.49 & & \\
\hline \multirow{6}{*}{$\mathrm{B}$} & Tackle & $9.71 * *$ & 3.20 & 0.33 & \multirow{6}{*}{$<0.001$} & \multirow{6}{*}{0.46} \\
\hline & Interception & 11.43 & 3.55 & 0.31 & & \\
\hline & Set piece & 17.14 & 4.63 & 0.27 & & \\
\hline & Opponent's error & $3.14^{\# \#}$ & 3.18 & 1.01 & & \\
\hline & Opponent's strike on goal & 15.00 & 7.12 & 0.47 & & \\
\hline & Save by the goalkeeper & 10.14 & 4.45 & 0.44 & & \\
\hline \multirow{4}{*}{$\mathrm{C}$} & Maintenance of ball possession & $40.57 * * *$ & 7.07 & 0.17 & \multirow{4}{*}{$<0.001$} & \multirow{4}{*}{0.90} \\
\hline & Counterattack & $15.00^{\# \# \#}$ & 4.93 & 0.33 & & \\
\hline & Strike on goal & 8.43 & 4.28 & 0.51 & & \\
\hline & Goal scored & 2.57 & 2.44 & 0.95 & & \\
\hline \multirow{4}{*}{$\mathrm{D}$} & Drawing & 19.57 & 16.94 & 0.87 & \multirow{4}{*}{0.93} & \multirow{4}{*}{0.10} \\
\hline & Winning by 1 point & 13.43 & 20.21 & 1.51 & & \\
\hline & Winning by 2 points or more & 18.71 & 25.76 & 1.38 & & \\
\hline & Losing & 14.86 & 14.72 & 0.99 & & \\
\hline
\end{tabular}

${ }^{*} p<0.005$ in relation to the half offensive $(d=1.8)$ and offensive sectors $(d=2.9)$;

${ }^{\#} p<0.001$ in relation to the defensive $(d=2.9)$, half defensive $(d=2.6)$, and half offensive sectors $(d=1.2)$

${ }^{* *} p<0.05$ in relation to set piece $(d=1.2)$; ${ }^{\# \#} p<0.02$ in relation to interception $(d=1.6)$, set piece $(d=2.3)$, and opponent's strike on goal $(d=1.4)$

*** $p<0.001$ in relation to counterattack $(d=2.7)$, strike on goal $(d=3.5)$, and goal scored $(d=4.6)$;

\#\#\# $p=0.001$ in relation to goal scored $(d=2.0)$

Table 3. Eigenvalues per component and total variance

\begin{tabular}{|c|c|c|c|c|c|c|c|c|c|}
\hline \multirow{2}{*}{ Components } & \multicolumn{3}{|c|}{ Initial eigenvalues } & \multicolumn{3}{|c|}{$\begin{array}{c}\text { Extraction sums } \\
\text { of squared loadings }\end{array}$} & \multicolumn{3}{|c|}{$\begin{array}{c}\text { Rotation sums } \\
\text { of squared loadings }\end{array}$} \\
\hline & Total & $\begin{array}{c}\% \\
\text { variance }\end{array}$ & $\begin{array}{c}\% \\
\text { cumulative }\end{array}$ & Total & $\begin{array}{c}\% \\
\text { variance }\end{array}$ & $\begin{array}{c}\% \\
\text { cumulative }\end{array}$ & Total & $\begin{array}{c}\% \\
\text { variance }\end{array}$ & $\begin{array}{c}\% \\
\text { cumulative }\end{array}$ \\
\hline 1 & 6.844 & 38.023 & 38.023 & 6.844 & 38.023 & 38.023 & 5.925 & 32.918 & 32.918 \\
\hline 2 & 5.949 & 33.050 & 71.073 & 5.949 & 33.050 & 71.073 & 4.651 & 25.841 & 58.759 \\
\hline 3 & 2.811 & 15.615 & 86.688 & 2.811 & 15.615 & 86.688 & 4.412 & 24.509 & 83.268 \\
\hline 4 & 1.541 & 8.560 & 95.248 & 1.541 & 8.560 & 95.248 & 2.156 & 11.980 & 95.248 \\
\hline 5 & 0.762 & 4.236 & 99.484 & & & & & & \\
\hline 6 & 0.093 & 0.516 & 100.000 & & & & & & \\
\hline 7 & 0.000 & 0.000 & 100.000 & & & & & & \\
\hline 8 & 0.000 & 0.000 & 100.000 & & & & & & \\
\hline 9 & 0.000 & 0.000 & 100.000 & & & & & & \\
\hline 10 & 0.000 & 0.000 & 100.000 & & & & & & \\
\hline 11 & 0.000 & 0.000 & 100.000 & & & & & & \\
\hline 12 & 0.000 & 0.000 & 100.000 & & & & & & \\
\hline 13 & 0.000 & 0.000 & 100.000 & & & & & & \\
\hline 14 & 0.000 & 0.000 & 100.000 & & & & & & \\
\hline 15 & 0.000 & 0.000 & 100.000 & & & & & & \\
\hline 16 & 0.000 & 0.000 & 100.000 & & & & & & \\
\hline 17 & 0.000 & 0.000 & 100.000 & & & & & & \\
\hline 18 & 0.000 & 0.000 & 100.000 & & & & & & \\
\hline
\end{tabular}


Table 4. Rotated component matrix for the variables of the ball possession recovery

\begin{tabular}{|c|c|c|c|c|}
\hline \multirow{2}{*}{ Variables } & \multicolumn{4}{|c|}{ Component } \\
\hline & 1 & 2 & 3 & 4 \\
\hline Offensive sector & $0.708^{*}$ & -0.330 & -0.459 & 0.298 \\
\hline Half offensive sector & 0.422 & -0.644 & -0.402 & -0.490 \\
\hline Half defensive sector & 0.610 & 0.345 & $0.697^{*}$ & -0.086 \\
\hline Half defensive sector & -0.058 & 0.522 & $0.733^{*}$ & 0.389 \\
\hline Tackle & 0.513 & $0.794^{*}$ & -0.056 & -0.139 \\
\hline Interception & 0.501 & 0.328 & 0.704 & 0.072 \\
\hline Set piece & -0.024 & $-0.944 *$ & -0.022 & 0.272 \\
\hline Opponent's error & $0.959^{*}$ & 0.078 & -0.132 & 0.074 \\
\hline Opponent's strike on goal & -0.145 & 0.117 & $0.960 *$ & 0.154 \\
\hline Save by the goalkeeper & -0.065 & $0.959 *$ & 0.226 & -0.004 \\
\hline Maintenance of ball possession & -0.262 & -0.080 & $0.956^{*}$ & 0.105 \\
\hline Counterattack & 0.170 & $0.775^{*}$ & 0.453 & 0.391 \\
\hline Strike on goal & $0.943^{*}$ & 0.222 & 0.203 & -0.086 \\
\hline Goal scored & 0.824 & 0.194 & -0.091 & 0.035 \\
\hline Drawing & -0.507 & 0.593 & 0.556 & -0.276 \\
\hline Winning by 1 point & 0.039 & -0.102 & 0.187 & $0.963 *$ \\
\hline Winning by 2 points or more & $0.941 *$ & -0.253 & -0.108 & -0.148 \\
\hline Losing & $-0.775^{*}$ & 0.218 & -0.053 & -0.584 \\
\hline
\end{tabular}

* A strong positive or negative correlation in factor loadings

Table 3 shows the 4 components that presented initial eigenvalues with a coefficient greater than 1 and were associated with a variance of $95 \%$ for all variables. Table 4 depicts the factors where factor 1 is related to the patterns of ball possession recovery in the offensive sector. Thus, the positive coefficients are related to a recovery close to the goal where the team that are intending to recover the ball want to score, whereas the negative coefficients correspond to a recovery away from that goal. Factor 2 is related to the tackle as an active way of ball recovery. The positive coefficients are directly linked to the player's direct recovery and the effects on the play after the acquisition of the ball, such as a counterattack. In contrast, the negative coefficients are related to set pieces as indirect recoveries. As of factor 3 , the positive coefficients show that ball recovery in the defensive sector was associated to recoveries after the opponent's strike on goal and the maintenance of the ball possession as a tactical behaviour after the recovery of the ball. Finally, factor 4 , which has the last variance, is only related to patterns of ball possession recovery when teams were winning by 1 point.

\section{Discussion}

The purpose of this study was to investigate the patterns of recovery of ball possession in youth futsal. The characteristics of ball possession recovery were assessed with respect to the way the players and the team recovered the ball, the location of the recovery on the field, the tactical behaviour after recovery of the ball, and the patterns of recovery when the teams were winning, drawing, or losing the matches. This set of variables characterizes the ball possession recovery as they affect the effectiveness of a futsal team in games and competitions [9-14].

It was observed that more balls were recovered in the defensive than in the offensive sector. This result can be explained on the basis of the dynamics of the futsal game itself, where teams in possession of the ball naturally expand and consequently make it difficult for the team that are defending to recover the ball, especially in youth games [23-25]. Accordingly, youth futsal teams show a greater fluctuation in the increase/ decrease of the effective space of play than professional futsal teams, generating more of the spaces between defending players that make recovery more difficult [26].

To solve this, the defending team can try to put pressure in their own offensive sector to recover the ball close to the goal they want to strike on [11]. However, considering that the defending team may not recover the ball, the team in possession should advance on the field, causing more difficulties in covering pass lines. Thus, the defenders of the team that are still defending would occupy spaces close to their own goal instead of pres- 
suring the ball carrier [27]. To improve the capabilities to recover the ball, teams should then train specific tactical principles and coherent behaviours, including compacting, closing empty spaces, and covering for similar situations, that is when the opposing team have the ball possession in their defensive sector [28].

More balls were recovered after set pieces for the attacking team, which helped to organize restart of play from a foul or the ball going out of play. However, tackle, interception, and saves by the goalkeeper also averaged approximately 10 ball recoveries each. Taking advantage of an error from the opponent was the only direct ball recovery that was least performed. In addition to accelerating the play, direct ball recoveries increase effectiveness and competitivity by creating more opportunities to score goals and win matches $[9,10,13,14]$.

One of the ways to increase the frequency of ball recovery by tackle, interception, and goalkeeper's saves is through the elaboration and application of representative tasks [3, 29, 30]. Representative tasks can be defined as activities that preserve the constraints inherent to the performance environment, as, for instance, space [31]. Decreasing the space of play promotes a greater number of transitions, that is, exchanges of ball possession, which can make teams recover the ball directly [32].

The maintenance of ball possession was the tactical behaviour more often performed after recovering the ball in comparison with the counterattack, strike on goal, and scoring goals. The results inherent to factor 3 of PCA reflect such behaviour since ball recovery in the defensive and half defensive sectors is associated with the maintenance of ball possession as a post-recovery tactical behaviour.

Thus, since defensive and half defensive sectors were sectors where more ball recoveries occurred, players circulated the ball in the search for empty spaces through the oscillation of the effective space of play [26]. In addition, the result of factor 2 of PCA reinforces this by showing that the counterattack is directly associated with ball recovery, in particular tackle and goalkeeper's defence.

No significant difference was found in the number of ball possession recoveries when the teams were winning, drawing, or losing. However, the result of factor 1 of PCA is related to the patterns of ball recovery in the offensive sector, which is associated with the opponent's error, strikes on goal, and victories with 2 goals or more. This denotes that the team were more secure in putting pressure on the opponent defence when they led on score, which provoked more errors if the opponents.

A limitation of this study is that the data collection was done with a single team that probably play with the same game model and train with the same program. Thus, in further studies on patterns of ball recovery, it is recommended to investigate more than 1 team.

Finally, in relation to the practical applicability of the research, the results show patterns of ball possession recovery in youth futsal that coaches can train by manipulating task constraints [33]. The manipulation of task constraints can refute or reinforce patterns, including ball recovery habits. Such an approach could retrieve the ball closer to the goal, increasing the number of tackles and interceptions or resulting in striking more often on the goal after ball recovery without decreasing the maintenance possession. Another important aspect is that teachers/coaches should offer information concerning the necessity of player behaviour and situational requirements [34].

\section{Conclusions}

Patterns of ball possession recovery were observed in youth futsal with respect to the way the ball was recovered; more balls would be earned after set pieces and fewer were recovered by taking advantage of the opponent's error. Patterns were also characterized by the location of the recovery on the field; more balls were recovered in the defensive sector, whereas fewer were earned in the offensive sector. The team preferred maintaining possession to scoring goals after recovering the ball. Furthermore, the result of the matches did not affect the number of balls recovered.

An association was observed between ball recoveries in the offensive sector, opponent's errors, strikes on goal, and victories with 2 or more goals differences. There was also an association between counterattacks, tackles, and saves by the goalkeeper. Finally, an association was demonstrated between ball recovery in the defensive sector, maintenance of ball possession after ball recovery, and ball recovery through the finalization of opponents on target.

\section{Disclosure statement}

No author has any financial interest or received any financial benefit from this research.

\section{Conflict of interest}

The authors state no conflict of interest.

\section{References}

1. Araújo D, Davids K. Team synergies in sport: theory and measures. Front Psychol. 2016;7(1):1449; doi: 10.3389/ fpsyg.2016.01449. 
2. Corrêa UC, Alegre FAM, Freudenheim AM, Dos Santos S, Tani G. The game of futsal as an adaptive process. Nonlinear Dynamics Psychol Life Sci. 2012;16(2):185203.

3. Santos R, Duarte R, Davids K, Teoldo I. Interpersonal coordination in soccer: interpreting literature to enhance the representativeness of task design, from dyads to teams. Front Psychol. 2018;9(1):2550; doi: 10.3389/ fpsyg.2018.02550.

4. McGarry T, Anderson DI, Wallace SA, Hughes MD, Franks IM. Sport competition as a dynamical self-organizing system. J Sports Sci. 2002;20(10):771-781; doi: 10.1080/026404102320675620.

5. Kelso JAS, Schöner G. Self-organization of coordinative movement patterns. Hum Mov Sci. 1988;7(1):27-46; doi: 10.1016/0167-9457(88)90003-6.

6. De Oliveira Bueno MJ, Caetano FG, Yonezawa MK, Grella AS, Cunha SA, Moura FA. How do futsal players of different categories play during official matches? A tactical approach to players' organization on the court from positional data. PLoS One. 2018;13(6):e0199619; doi: 10.1371/journal.pone.0199619.

7. Moura FA, Barreto Martins LE, de Oliveira Anido R, de Barros RML, Cunha SA. Quantitative analysis of Brazilian football players' organisation on the pitch. Sports Biomech. 2012;11(1):85-96; doi: 10.1080/14763141. 2011.637123.

8. Moura FA, van Emmerik REA, Santana JE, Barreto Martins LE, de Barros RML, Cunha SA. Coordination analysis of players' distribution in football using crosscorrelation and vector coding techniques. J Sports Sci. 2016;34(24):2224-2232; doi: 10.1080/02640414.2016. 1173222 .

9. Miloski B, Pinho JP, de Freitas CG, Marcelino PR, de Arruda AFS. Which technical-tactical actions performed in futsal matches can discriminate the result of winning or defeat? [in Portuguese]. Rev Bras Educ Fís Esporte. 2014;28(2):203-209; doi: 10.1590/180755092014000200203.

10. Barreira D, Garganta J, Guimarães P, Machado J, Anguera MT. Ball recovery patterns as a performance indicator in elite soccer. J Sports Eng Technol. 2014;228(1): 61-72; doi: 10.1177/1754337113493083.

11. Reis M, Almeida M. Soccer, art, and science: creating a play model [in Portuguese]. Natal: Editora Primeiro Lugar; 2019.

12. Almeida CH, Ferreira AP, Volossovitch A. Effects of match location, match status and quality of opposition on regaining possession in UEFA Champions League. J Hum Kinet. 2014;41(1):203-214; doi: 10.2478/hukin2014-0048.

13. Liu H, Gomez M-Á, Lago-Peñas C, Sampaio J. Match statistics related to winning in the group stage of 2014 BrazilFIFA World Cup.J Sports Sci.2015;33(12):12051213; doi: 10.1080/02640414.2015.1022578.

14. Liu H, Hopkins WG, Gómez M-A. Modelling relationships between match events and match outcome in elite football. Eur J Sport Sci. 2016;16(5):516-525; doi: 10.1080/17461391.2015.1042527.

15. Reis M, Santos J, Matos M, Cruz T, Vasconcellos F, Almeida M. Assessment of the performance of novice futsal players in the execution of futsal-specific motor skills. Hum Mov. 2019;20(3):29-37; doi: 10.5114/hm.2019. 83994.

16. Costa IT, Garganta J, Greco PJ, Mesquita I, Maia J. System of tactical assessment in soccer (FUT-SAT): development and preliminary validation. Motricidade. 2011;7(1):69-83; doi: 10.6063/motricidade.121.

17. Dancey CP, Reidy J. Statistics without mathematics for psychology [in Portuguese]. Porto Alegre: Penso; 2013.

18. Fernandez-Navarro J, Fradua L, Zubillaga A, Ford PR, McRobert AP. Attacking and defensive styles of play in soccer: analysis of Spanish and English elite teams. J Sports Sci. 2016;34(24):2195-2204; doi: 10.1080/ 02640414.2016.1169309.

19. MacCallum RC, Widaman KF, Zhang S, Hong S. Sample size in factor analysis. Psychol Methods. 1999;4(1): 84-99; doi: 10.1037/1082-989X.4.1.84.

20. Kaiser HF. An index of factorial simplicity. Psychometrika. 1974;39(1):31-36; doi: 10.1007/BF02291575.

21. Kaiser HF. The application of electronic computers to factor analysis. Educ Psychol Meas. 1960;20(1):141-151; doi: 10.1177/001316446002000116.

22. Robinson G, O’Donoghue P. A weighted kappa statistic for reliability testing in performance analysis of sport. Int J Perf Anal Sport. 2007;7(1):12-19; doi: 10.1080/ 24748668.2007.11868383.

23. Corrêa UC, Vilar L, Davids K, Renshaw I. Informational constraints on the emergence of passing direction in the team sport of futsal. Eur J Sport Sci. 2014;14(2):169176; doi: 10.1080/17461391.2012.730063.

24. Oppici L, Panchuk D, Serpiello FR, Farrow D. Futsal task constraints promote transfer of passing skill to soccer task constraints. Eur J Sport Sci. 2018;18(7):947-954; doi: 10.1080/17461391.2018.1467490.

25. Oppici L, Panchuk D, Serpiello FR, Farrow D. Longterm practice with domain-specific task constraints influences perceptual skills. Front Psychol. 2017;8(1): 1387; doi: 10.3389/fpsyg.2017.01387.

26. De Oliveira Bueno MJ, Caetano FG, de Souza NM, Cunha SA, Moura FA. Variability in tactical behavior of futsal teams from different categories. PLoS One. 2020; 15(3):e0230513; doi: 10.1371/journal.pone.0230513.

27. Laakso T, Davids K, Liukkonen J, Travassos B. Interpersonal dynamics in 2-vs-1 contexts of football: the effects of field location and player roles. Front Psychol. 2019;10(1):1407; doi: 10.3389/fpsyg.2019.01407.

28. Dos Reis MAM, do Amaral Vasconcellos FV, de Almeida MB. Performance and tactical behavior of youth soccer players. Rev Bras Cineantropom Desempenho Hum. 2017;19(2):242-250; doi: 10.5007/1980-0037. 2017v19n2p242.

29. Araújo D, Dicks M, Davids K. Selecting among affordances: a basis for channeling expertise in sport. In: 
Cappuccio ML (ed.), Handbook of embodied cognition and sport psychology. Cambridge: MIT Press; 2018; 557-580.

30. Travassos B, Duarte R, Vilar L, Davids K, Araújo D. Practice task design in team sports: representativeness enhanced by increasing opportunities for action. J Sports Sci. 2012;30(13):1447-1454; doi: 10.1080/02640414. 2012.712716.

31. Brunswik E. Perception and the representative design of psychological experiments. Berkeley: University of California Press; 1956.

32. Olthof SBH, Frencken WGP, Lemmink KAPM. Matchderived relative pitch area changes the physical and team tactical performance of elite soccer players in smallsided soccer games. J Sports Sci. 2018;36(14):1557-1563; doi: 10.1080/02640414.2017.1403412.

33. Chow JY, Davids K, Button C, Shuttleworth R, Renshaw I, Araújo D. The role of nonlinear pedagogy in physical education. Rev Educ Res. 2007;77(3):251-278; doi: 10.3102/003465430305615.

34. Wałach-Biśta ZM. What do we want and what do we get from the coach? Preferred and perceived leadership in male and female team sports. Hum Mov. 2019;20(3): 38-47; doi: 10.5114/hm.2019.79734 